\title{
UNAMUNO: LA FAMILIA Y SU MISIÓN EDUCATIVA ${ }^{1}$
}

\author{
Emanuel José Maroro Dos Santos \\ emanuel.ejms.santos@gmail.com
}

\begin{abstract}
RESUMEN / ABSTRACT
El presente estudio intenta desvelar la concepción unamuniana de familia tal como nuestro autor la concibe en sus escritos teóricos, literarios y autobiográficos. Siendo un trabajo histórico-hermenéutico, se centrará en la obra escrita del autor que constituye el objeto último de la presente investigación. Bien, por ello el horizonte sociológico que dio origen a la reflexión unamuniana, siendo considerado, solo halla su sentido teórico en cuanto que permite la clarificación de la posición filosófico-educativa de Unamuno. Con vistas a clarificar su pensamiento educativo, optaremos por definir a priori su concepción de familia para que, apoyados en su caracterización, podamos comprender sus peculiares concepciones de maternidad y paternidad que, pese a su actual descontextualización, pueden recuperar, si debidamente enfocadas, los rasgos o dimensiones espirituales de la educación contemporánea, que exige la formación del yo-íntimo y del yo-público de las jóvenes generaciones, esto es, su educación ético-normativa y político-jurídica, que, hoy día, se viene pidiendo a la escuela.
\end{abstract}

Palabras ClaVe: familia, maternidad, paternidad, yo-interior y yo-exterior.

\section{UNAMUNO: FAMILY AND ITS EDUCATIONAL MISSION}

The present study attempts to reveal Unamuno's conception of family as conceived in his theoretical, literary and autobiographical writings. As a historical and hermeneutical work, it will focus on the written work of the author who is the ultimate object of the present investigation. Thus, the sociological horizon that gave rise to Unamuno's reflection, when considered, can only find its theoretical sense in the fact that it allows the clarification of the thinker's philosophical and educational position. In order to clarify his educational thought, we chose to previously define Unamuno's conception of family so as to, based on their characterization, we can understand his peculiar conceptions of maternity and paternity. Despite its current decontextualization, and if properly targeted, such peculiar conceptions can recover the traits or spiritual dimensions of contemporary education, which requires the formation of the intimate self and the public self of the younger generations, i.e. their ethical-normative and political-legal education, which, nowadays, has been demanded of school.

KEYWORDS: Family, maternity, paternity, inner self and outer self.

Trabajo apoyado por la FCT. Fundação para a ciência e a tecnologia, Lisboa, Portugal. 


\section{Introducción}

Y donde la familia no tiene raíces hondas, ni el espíritu abismos en que refugiarse, eso ha de ser fatal (Unamuno 1996, 424).

$\widehat{R A}$ El presente estudio está estructurado en torno a cuatro aspectos interdependientes que procuran determinar la concepción unamuniana de familia, cuya misión y funciones educativas, en cuanto expresión de su época histórica, nos permiten vislumbrar el rol pedagógico que cada uno de los progenitores está llamado a desarrollar en la educación de sus hijos.

Primero, y enfocando su pensamiento desde una perspectiva general, analizaremos los rasgos esenciales del mencionado concepto, procurando desvelar el papel intransmisible que los padres tienen en la formación de las nuevas generaciones. En este aspecto, la crítica de Unamuno a la educación burguesa de finales del siglo XIX y principios del XX es bastante reveladora de su pensamiento en tanto cuanto hace patente la importancia que concedió a la misma como fundamento de la sociedad.

Después, intentaremos desvelar sus sui generis concepciones de maternidad y de paternidad, y sus significados pedagógicos. Don Miguel, al distinguir la naturaleza biológica y espiritual de los progenitores, consideró que la madre y el padre deberían tener papeles educativos diferenciados. A este propósito, subrayamos que la correcta determinación de su pensamiento pedagógico, muy influenciado por el ambiente sociológico de su época histórica, nos permitirá percibir, por abstracción, las dos dimensiones esenciales de la educación familiar: la ético-normativa, inherente a la formación del yo-interior, y la cívica o jurídico-política, relativa a la formación del yopúblico, lo que nos ayudará en la interpretación de los hilos educativos que, actualmente, las familias están llamadas a desarrollar en la formación de sus hijos.

Y, en un último apartado, analizaremos las consideraciones unamunianas relativas a las niñeras y a las nodrizas, y a los personajes extranaturales que se inculcan a los niños para poder gobernarlos mejor. Unamuno, en cuanto educador de su pueblo, después del célebre Desastre del 98, quiso que todos sus conciudadanos se comprometiesen con la regeneración de su país, sobre todo las familias. Fue por ello que criticó todo lo que hacía descuidar a los padres su misión y funciones pedagógicas. Para nuestro autor, como veremos, las familias tienen una función esencial en la conservación y perpetuación tanto biológica como espiritual de su pueblo, dado que, en este aspecto no puede haber concesiones, sobra, para don Miguel, todo lo que aleja a los padres de sus obligaciones antropagógicas*.

Se trata de un neologismo. 


\section{La familia: el fundamento de la sociedad}

Es ella, sí, es ella-siguió diciéndose-, es ella, es la misma, es la que yo buscaba hace años, aun sin saberlo; es la que me buscaba. Estábamos destinados uno a otro en armonía preestablecida; somos dos mónadas complementaria una de otra. La familia es la verdadera célula social. Y yo no soy más que una molécula. ¡Qué poética es la ciencia, Dios mío! ¡Madre, madre mía, aquí tienes a tu hijo, aconséjame desde el cielo! ¡Eugenia, mi Eugenia!... (Unamuno 1967, 570).

Si se analizan las reflexiones de Unamuno acerca de la familia, verificamos, casi de inmediato, que yuxtapuestas a sus muy sui generis concepciones de paternidad, maternidad y filialidad, se ubican las críticas que Unamuno dirigió a la realidad social de su época, esto es, se ubican sus críticas hacia la forma cómo se vivía y concebía la familia, en el periodo finisecular. Su crítica principal, considerándola en términos generales, se dirigió a aquellos padres que desatendían a sus hijos, ya sea a raíz de sus necesidades económicas, ya sea a raíz de sus “devaneos y distracciones” (Unamuno 1971, 91). En este aspecto, Unamuno es categórico: nada ni nadie puede ser una disculpa para el abandono de los hijos. Y de tal forma lo hizo constar que, en su discurso pronunciado en Orense, en junio de 1903, llegó a afirmar que una de las principales causas de la decadencia de Roma se debió al hecho de que las ricas familias romanas hubiesen entregado la educación de sus hijos a "pedagogos de alquiler", ésta es su expresión, es decir, a los esclavos, cuya nefasta consecuencia se concretó en la formación de "tiranuelos holgazanes" (Unamuno 1971, 91). Y al plantear de este modo el problema quiso hacer patente que es deber fundamental de los padres el preocuparse de la educación de sus hijos, en la medida en que solo en la educación radica el fundamento de la formación ético-normativa del hombre o, de forma más radical, el fundamento del propio hombre.

Ahora bien, para Unamuno, que asume que la educación es conditio sine qua non de la propia existencia espiritual del hombre, el ideal de la educación burguesa debería ser, inmediatamente, condenado, ya que se oponía, de forma directa, al telos de la propia educación. Es más que conocido su ensayo "Introducción a algunas consideraciones sobre la educación burguesa", de 1895, donde Unamuno se propuso criticar dicho ideal educativo. Sin embargo, su posición crítica hacia el mismo puede encontrarse ya tres años antes, en la carta que envió a su paisano Juan Arzadun, el 17 de junio de 1892. En dicha misiva, Unamuno no pudo ser más claro en su toma de posición cuando refirió que era un grave error el creer que era más importante dar un determinado capital o carrera a un hijo que educarlo ética y normativamente (Unamuno 1996, 38). Pues bien, fue a partir de este mismo parecer que Unamuno, en el susodicho ensayo de 1895, afirmó que el capitalismo tendía a destruir el sentido de la "educación" y del propio "deber paternal" (Unamuno 1971, 490-491), ya que los padres, al colocar todo su empeño en dejar a sus hijos un determinado capital, terminaban por olvidar que su función principal, en cuanto padres, era la de educar a sus hijos en todas las dimensiones de la naturaleza humana. Para Unamuno, hay que subrayarlo, lo decisivo no era dar un título académico a un hijo, sobre todo en una época en que aquél ejercía un determinado monopolio sobre la sociedad, es decir, en una época en que poseerlo significaba poder ejercer una determinada profesión de prestigio social, ni menos, 
todavía, dar un capital para que aquéllos no necesitasen trabajar (Unamuno 1971, 490); lo fundamental era educar a los hijos, formarlos normativamente, a partir de la tradición espiritual de su familia y, por extensión, a partir de la tradición espiritual de su país; lo decisivo era, pues, que los padres no lo fuesen solo biológicamente, sino también espiritualmente, o sea, que el espíritu de los padres perviviese en el alma de sus hijos y los alimentase en el desarrollo ético-normativo de sus personas; en suma, lo esencial era hacer hombres y no capitalistas (Unamuno 1971, 490).

Si estudiamos objetivamente los problemas pedagógicos, reconocemos que uno de los mayores obstáculos para el progreso de la enseñanza científica y técnica es la existencia de un monopolio de los títulos académicos. Aquí en España, al menos, los padres se preocupan de que sus hijos consigan un título, lo cual, por lo general, no quiere decir que les importe la sabiduría, porque en realidad, las personas que tienen una profesión en monopolio viven más de su título que de su sabiduría. El título de doctor se ha convertido en una especie de título de nobleza, una especie de coleta china de la que se cuida [sic] brillantemente nuestros mandarines europeos. Por lo general, el título no significa que se poseen conocimientos, sino la posesión de un capital en monopolio cuyas rentas son en su mayor parte garantizadas por el estado burgués; significa también que uno ha podido invertir un capital en metálico para multiplicarlo (Unamuno 1971, 491).

Si se analiza, ahora, su novela Paz en la guerra, de 1897, verificamos que Unamuno, en dicha obra, se detiene a considerar no solo el ideal educativo liberal, inherente a la familia Arana, sino también el ideal educativo católico, el que preside la formación de la personalidad de Ignacio. Si dejamos a un lado el primer ideal (Unamuno 1967, 101), para centrarnos en exclusiva en el segundo, verificamos, por de pronto, que Unamuno pretendió establecer un nexo de causalidad entre la educación religiosa de Ignacio y su personalidad, al afirmar que sus primeros años en casa de sus padres "modelaron" el "espíritu virgen de Ignacio" (Unamuno 1967, 99). Unamuno, después de establecer dicho nexo de causalidad, intentó cristalizar los fundamentos de la educación católica de Ignacio, al afirmar que ésta se reducía (1) a besar [...] la mano a sus padres al acostarse y al levantarse, (2) a no tutearlos, (3) y a "inculcar" el "santo temor a Dios" (Unamuno 1967, 99). Cabría subrayar, aún, que en la educación de Ignacio tuvo, igualmente, un papel decisivo la influencia de su tío Pascual, el cura de la familia, ya que bajo su influencia Ignacio no solo leía de ordinario el santoral, sino que aprendía también el "valor de los mártires", como el de san Lorenzo, la leyenda de las Cruzadas (Unamuno 1967, 104), y la santidad de la castidad (Unamuno 1967, 113).

Pues bien, si se tiene en consideración el desarrollo existencial de dicho personaje, verificamos que este tipo de ideal educativo, en la forma como era concebido e interpretado en la época finisecular, tenía innúmeras consecuencias negativas que, en Ignacio, se consubstanciaron (1) en la incapacidad de mirar el hombre más por dentro que a partir de sus ideas puramente externas, (2) la caída en el pecado de la concupiscencia y (3) la muerte en el campo de la batalla, en cuanto defensor de la causa carlista.

Entonces tomó el tío Pascual a su sobrino de su cuenta, llevóle consigo de paseo alguna que otra vez para mejor aleccionarlo. Queríale cuanto él podía querer 
según la carne, pero sobre todo se empeñaba en formar sus ideas, considerándole como materia de educación. Las ideas, lazo social, eran a sus ojos todo; jamás le ocurrió mirar a un hombre por más adentro ni ver en él otra cosa que un miembro de la Iglesia o un extraño a ella (Unamuno 1967, 113).

Pero, ¿qué ideal educativo familiar nos propuso Unamuno? Lo primero que hay que afirmar, y en esto estamos en plena sintonía con Ricardo Senabre, es que, para el rector salmantino, tal como lo subraya en su Niebla, de 1914, por la boca de Augusto Pérez, la familia es la célula de la sociedad, esto es, es su primer elemento, el más básico (Senabre 1989, 174). Y por serlo mereció para Unamuno largas páginas de análisis y reflexión, sobre todo en lo que concierne a la definición de los conceptos de maternidad, paternidad y filialidad. Empero, si es la célula de la sociedad, ¿cómo pensarla? Pues bien, pese al hecho de que Unamuno no lo haya llegado a afirmar, de forma categórica, su concepción de familia arraiga en sus vivencias familiares y, por ende, en su declarado cristianismo. Unamuno es un autor cristiano, es consabido. Pero no basta saberlo, hay que sacar, también, todas las consecuencias que dicho aspecto implica. Asimismo, debemos afirmar que su educación familiar, donde tuvo un gran peso el catolicismo popular español, en las figuras de su madre doña Salomé y de su abuela doña Benita, fue determinante en la formación de su ideal educativo. Empero, su cristianismo no se hace sentir tan solo a partir de la influencia del catolicismo popular español, que recibió en el seno de su familia, sino también a partir de la influencia que el protestantismo tuvo en su formación intelectual y que lo hizo alejar, en variadísimos puntos, del "ortodoxismo" de la Iglesia católica. Por ello creemos que, en lo que se refiere a su modelo de familia, Unamuno es, en cierto modo, un defensor del modelo católico tradicional leído e interpretado a la luz del concepto de libertad, que señala su acercamiento al liberalismo. O sea, y como lo refiere también Delgado Criado, el modelo educativo familiar defendido por Unamuno es el de la familia de Gertrudis, de su novela La tía Tula, de 1921, ya que la forma como don Primitivo educó a Tula y a Rosa, o la forma como Tula educó a sus sobrinos, constituye, grosso modo, el modelo educativo familiar defendido por Unamuno (Delgado Criado 1973, 200). Decimos grosso modo, por cuanto el relato novelesco unamuniano caricaturiza, de forma consciente, las figuras de Tula, Rosa y Ramiro. Asimismo, los padres españoles han de ser, fundamentalmente, los padres espirituales de sus hijos, educándolos a la luz del espíritu de sus familias, que ha de ser un reflejo individualizado del espíritu de su propio pueblo, esencialmente estructurado en torno al cristianismo. O, dicho de otro modo, el ideal educativo familiar propuesto por don Miguel supone la activación del concepto de persona cuya ipseidad espiritual ha de ser una expresión del espíritu del pueblo individualizado en el espíritu de cada familia y de cada uno de sus miembros. Hay, pues, en Unamuno, un manifiesto deseo de una educación étnico-nacional, en la cual los individuos, en cuanto personas, han de ser expresión del espíritu de la comunidad a que pertenecen. A este propósito, cabría subrayar que la determinación espiritual de los individuos a partir de la ipseidad étnica no restringe o niega la libertad de las nuevas generaciones sino que la posibilita, ya que, para Unamuno, solo hay libertad dentro de un determinado horizonte espiritual. Innecesario será decir que, según Unamuno, el espíritu del pueblo, homogéneo en la heterogeneidad, progresa a partir del concepto de individuación que posibilita la libertad y unicidad de los individuos. 
Ahora bien, una vez determinado el modelo educativo familiar de Unamuno, cabe establecer, ahora, el modo cómo los padres han de educar a sus hijos. Y en este aspecto estamos de acuerdo con Morón Arroyo, para quien la educación familiar, la educación que los padres han de dar a sus hijos, ha de realizarse a partir de las realidades de la imitación y del ejemplo (Morón Arroyo 1997, 25-26). Para dicho comentador, con el cual estamos en plena sintonía interpretativa, Unamuno transita de una concepción de sociedad como una realidad intramental, que le imponía su concepto de intrahistoria, hacia una concepción de la misma como una realidad intermental, substituyendo el concepto vago de psique colectiva, como principio de socialización, a favor del concepto de imitación. Es imitando los ejemplos de sus padres que los hijos aprenderán a ser hombres y mujeres, y a formar sus caracteres. No nos extraña, pues, que Unamuno haya afirmado, en algunos pasajes de su extensa obra, de los cuales podríamos destacar el susodicho ensayo "Introducción a algunas consideraciones sobre la educación burguesa", de 1895, e, incluso, su prólogo a la obra de Bunge "La educación”, de 1902 (Unamuno 1966, 1021), que es el deber de los padres “corregir", a través de la educación, los defectos del carácter que, por herencia fisiológica, hayan recibido sus hijos.

Cuando el sentido de lo que uno es representa poco para la prosperidad individual, se oscurece el verdadero deber del padre hacia el hijo, la herencia fisiológica. Los deberes del padre se basan fundamentalmente en que su hijo es el suyo y no el de otro, y en esto es como él y no diferente; porque el padre no solo es responsable de la existencia del hijo, sino también y sobre todo de su carácter y sus cualidades. El hijo ha recibido por la herencia fisiológica tal o cual carácter, y el padre debe, a través de la educación y de la influencia del medio social, tratar de corregir los defectos de éste. La verdadera función de la familia es ésta: trasformar al animal humanizado en hombre antes de que éste entre en la vida social y se acople a ella (Unamuno 1971, 490).

\section{La maternidad y la formación del "yo interior"}

No quiso que a la niña se le ocupase demasiado en aprender costura y cosas así. “¿Labores de su sexo? -decía-, no, nada de labores de su sexo; el oficio de una mujer es hacer hombres y mujeres, y no vestirlos" (Unamuno 1967, 1071).

Más que conocidas, y muy estudiadas, son las concepciones unamunianas de maternidad, paternidad y filialidad. Y todas ellas se refieren a una realidad particular de la educación familiar: las dos primeras se refieren a la formación humana y cívica de los hijos, y la última al resultado de dicha formación. Dado que, en términos educativos, la maternidad, tal como es concebida e interpretada por Unamuno, se presenta como una realidad más primaria y radical que la paternidad, quisiéramos empezar por analizarla, intentando cristalizar su esencia a la luz de lo que Unamuno nos dice en sus ensayos y obras literarias. Planteemos, pues, las preguntas que estructuran el presente apartado: ¿qué es la maternidad?, ¿cuáles son sus funciones o finalidad? Lo primero que hay que subrayar es que la educación familiar de Unamuno fue, señaladamente, matriarcal, por cuanto ha quedado huérfano de padre a la temprana edad de seis años. Y este hecho no 
puede ni debe ser soslayado, ya que tuvo consecuencias decisivas en la formación de su pensamiento, mayormente en sus concepciones, bien diferenciadas, de maternidad y de paternidad. Por otro lado, dicho hecho, el de que Unamuno fuese educado, en su niñez, por su madre, doña Salomé, y abuela, doña Benita, a raíz de la muerte temprana de su padre, don Félix, nos permite comprender mejor sus sui generis concepciones de maternidad y paternidad, que hoy en día nos podrán parecer un poco anacrónicas y un tanto rígidas. Pero, más allá de su manifiesta rigidez y poca adaptación a los tiempos modernos, nos permiten comprender mejor la importancia y la esencia de los elementos femenino y masculino o, por lo menos, de lo que estos elementos significan en la formación de las jóvenes generaciones.

Para Unamuno, hombre y mujer, más allá del hecho de que los considere como dos seres con igual importancia antropológica, tienen misiones bien diferentes en la educación de sus hijos y, por ende, en la sociedad. Unamuno no escamotea los principios antropológicos que adopta a la hora de empezar sus reflexiones. Si somos rigurosos en el análisis de su obra, verificamos que nuestro autor parte de la diferencia somática que separa el hombre de la mujer. Y al hacerlo, afirmó que del mismo modo como son diferentes en sus cuerpos, son igualmente diferentes en sus espíritus y, por ende, en la forma de relacionarse con el mundo. El biologismo, pues, a juicio de Unamuno, condiciona la ipseidad somática y espiritual del hombre y de la mujer. Ahora bien, fue a partir de este postulado previo que Unamuno afirmó, en su ensayo "A la señora Mab", de 1908, de forma más que tajante, que el organismo femenino, al estar organizado para “concebir, gestar y amamantar", hizo que la mujer, desde las sociedades más primitivas, no siguiese a los hombres en la guerra y en la caza, quedándose en casa a cuidar de los hijos, hecho que implicó la formación de su intelectualidad y espiritualidad caseras, de "aplicación concreta" y atenta a "detalles" y "minuciosidades", que no les permite, por ejemplo, la "alta especulación filosófica" (Unamuno 1968a, 485). Y después de explicitar dicha idea, concluyó que el papel de la mujer en la sociedad ha de tener siempre en consideración dicha diferencia biopsíquica (Unamuno 1968a, 486), lo que implicará, por ejemplo, en la literatura, el desarrollo de un "tono genuinamente femenino" (Unamuno 1968a, 487). Pero, el hecho de que Unamuno vinculase el papel social de la mujer a su naturaleza somática y espiritual no implica que a la mujer unamuniana le esté permitido todo. Unamuno es, en este aspecto, un pensador tradicional, muy influenciado por los valores de la Iglesia católica, sobre todo en lo que toca a la noción de familia y del cuerpo humano, y, por ello, todo tipo de feminismo le repugna, como lo puso de relieve en innúmeros pasajes de su obra, dentro de los cuales se destaca, por ejemplo, su ensayo "La mujer gaditana”, de 1903 (Unamuno 1968a, 1088). ¿Cuál es, pues, el papel social de la mujer unamuniana? Dado que, por un lado, ésta está organizada somáticamente para concebir, gestar y amamantar, y dado que, por otro, su cuerpo le condiciona su intelectualidad y espiritualidad, su papel habrá de ser el de cuidar de los niños, el de educarlos, según el espíritu de su tradición familiar. Basta no pasar por alto el discurso que Unamuno pronunció en Orense, en junio de 1903, para percibir, con gran claridad, el papel social que Unamuno concedía a la mujer. En dicha ocasión, nuestro autor, casi en la misma línea de Rousseau, afirmó que la mujer española debería rechazar tanto las nodrizas como los "pedagogos de alquiler", 
puesto que su papel fundamental, en cuanto madres, era el de amamantar y educar a sus hijos (Unamuno 1971, 91). En dicha toma de posición, se hace notar el talante intelectual de Unamuno, que, en la misma línea de la Iglesia católica, sobre todo en lo que concierne a la concepción de la Sagrada Familia, percibe como deber fundamental de la mujer/madre la insigne tarea de criar y educar a sus hijos. No nos extraña, pues, que en el mencionado discurso Unamuno protestase contra el hecho de que se educase a la "mujer" para "monja" o para "novia" y nunca para "madre" (Unamuno 1971, 92). Cabe afirmar, tan solo, que, para el rector salmantino, tal como lo pone de relieve en su ensayo "El resorte moral", de 1906, la "mujer" es el "arca" de la tradición popular, el "principio de continuidad" de su propio pueblo, ya que su función, en cuanto madre, es la de educar a sus hijos según el espíritu de su familia, que ha de ser una expresión individualizada del Volksgeist español.

La mujer es el verdadero principio de continuidad de un pueblo, el arca de sus más preciadas y más profundas tradiciones. Y en un país que se constituye de nuevo, en un país que lucha por adquirir personalidad -único modo de gozar de verdadera independencia y de lograr duración-; en un país que necesita de una tradición fuerte, como necesita de bien arraigados árboles en sus orillas todo río torrentoso y de incierto cauce; en un país así, pocas cosas, si es que algunas, son más vitales que las preocupaciones que embarguen el espíritu de sus mujeres. Y si su preocupación principal, en las clases adineradas, fuera eso que llama la vida de sociedad y en que la iglesia está al par del teatro y no es sino otra forma de éste, si las creencias -a cualquier cosa se suele llamar creer-y el culto formaran parte de las prescripciones del buen tono y de la llamada buena educación, entonces el país en que eso suceda está amenazado de muy serios peligros (Unamuno 1968a, 280-281).

En lo que dice respecto a la concepción unamuniana de la mujer, a la definición de sus funciones y finalidad existenciales, y a las influencias que han operado en la formación del pensamiento de Unamuno, la obra literaria de nuestro autor tiene una palabra muy importante que decir. Por de pronto, percibimos, con claridad, que los personajes Josefa Ignacia, de Paz en la guerra, de 1897; que Marina del Valle, de Amor y pedagogía, de 1902, y que Gertrudis, de La tía Tula, de 1921, son tres ejemplos de maternidad para Unamuno, formados todos ellos a partir de los valores cristianos. Si nos detenemos, en primer lugar, en Josefa Ignacia percibimos que dicho personaje novelesco está animado por los valores católicos y que, en su ansia de maternidad, pide constantemente a Dios la gracia de un hijo, según la carne. En la misma línea se ubica Marina del Valle, pero con una diferencia fundamental. Marina no pide a Dios la gracia de un hijo sino que lo intenta educar según los preceptos del catolicismo popular español, por oposición a la acción educadora de su padre, don Avito Carrascal, que lo pretende educar en torno a los principios sociológicos vigentes en la época finisecular. La acción educativa de Marina se concreta, pues, en hablar de Dios, de la Virgen, de Cristo, de los ángeles y de los santos, de la gloria y del infierno [a su hijo, Apolodoro], enseñándole a rezar (Unamuno 1967, 344). Y misma actitud puede hallarse en Tula. Pero con una nueva diferencia, ya que su acción educadora no se consustancia tanto en hablar de Dios, de la Virgen, de los ángeles y de los santos, como en presentarse como un ejemplo a 
imitar, a través de la transparencia de su vida, cuyos valores asientan en el cristianismo prefigurado en la imagen de la Virgen María. Su misión era, pues, hacer hombres a partir del espíritu de su familia, que se trasmitía por vía femenina de generación en generación; espíritu que, en su matriz axiológica, era un reflejo de la tradición espiritual española, esto es, del catolicismo popular.

- Fué nuestro padre -le dijo a su hermana- y jamás le oímos una palabra más alta que la otra.

- ¡Claro! -exclamó Rosa-; como que siempre nos dejó hacer nuestra santísima voluntad.

- Porque sabía, Rosa, que su sola presencia santificaba nuestra voluntad. Fué nuestro padre; él nos educó. Y para educarnos le bastó la transparencia de su vida, tan sencilla, tan clara...

- Es verdad, sí -dijo Rosa, con los ojos henchidos de lágrimas-, como sencillo no he conocido otro.

- Nos habría sido imposible, hermana, habernos criado en un hogar más limpio que éste.

- ¿Qué quieres decir con eso, Tula?

- Él nos llenó la vida casi silenciosamente, sin decirnos palabra, con el culto de la Santísima Virgen Madre, y con el culto también de nuestra madre, su hermana, y de nuestra abuela, su madre. ¿Te acuerdas cuando por las noches nos hacía rezar el rosario, cómo le cambiaba la voz al llegar a aquel padrenuestro y avemaría por el eterno descanso del alma de nuestra madre, y luego aquellos otros por el de su madre, nuestra abuela, a la que no conocimos? En aquel rosario nos daba madre $\mathrm{y}$ en aquel rosario te enseñó a serlo.

- ¡Y a ti, Tula, a ti! -exclamó entre sollozos Rosa.

- ¿A mí?

- ¡A ti, sí, a ti! ¿Quién, si no, es la verdadera madre de mis hijos? (Unamuno 1967, 1057)

Para el rector salmantino, ser mujer es ser madre y ser madre es ser la primera educadora de la humanidad. Su acción educadora ha de ser fundamentalmente ético-normativa, alimentada en el suelo espiritual de su familia y, por ende, en el de su pueblo, lo único que debe tenerse en cuenta en la formación del carácter de las jóvenes generaciones. Pues bien, si se miran con algún detalle dichas tesis unamunianas estamos obligados a rechazar algunos elementos. En primer lugar, ser mujer no es ser madre de forma inmediata y correlativa. La mujer puede o no ser madre, ésa es una decisión suya. Porque ser madre implica tanto una determinación fisiológica como una decisión existencial. Y Unamuno parece olvidar este último aspecto, por cuanto cree que el conato de persistencia impone, en términos de realización existencial, que el hombre y la mujer sean, simultáneamente, padre y madre. Y esto, hay que reafirmarlo, es un error, en la medida en que los binomios hombre y padre, y mujer y madre no son consustanciales ni coextensivos. Pero hay otro error en el planteamiento de Unamuno. Sin duda que el cuerpo condiciona el espíritu. Sería un error afirmar que el cuerpo de la mujer y del hombre no condicionan la forma como éstos se relacionan con el mundo. Es por ello que el ser mujer o el ser hombre, que sus ipseidades, es decir, que sus temperamentos e idiosincrasias, son, en un primer momento, expresiones de sus cuerpos. Asimismo, 
somos obligados a concluir, y en esto seguimos a Unamuno, que la mujer, la que concibe, gesta y amamanta al niño, tiene una relación hacia él diferente de la del padre. Hombres y mujeres, porque son somáticamente diferentes, tienen personalidades y relaciones con el mundo diferentes, y por ello relaciones parentales diferentes. Lo que cabe saber es si eso implica o no dos tipos diferentes de acciones educativas. ¿Serán diferentes las misiones educativas del padre y de la madre? ¿Tendrá la madre la misión de educar en humanidad y el padre en civilidad? Para Unamuno, sí. Ya lo hemos visto. Para nosotros, no. En nuestras sociedades actuales, en las cuales padre y madre trabajan, es decir, en las cuales padre y madre son, simultáneamente, dos seres civiles y hogareños, la educación para la civilidad y para la humanidad debe ser hecha por los dos. No puede decirse que la misión de la madre sea la de educar en humanidad, la de formar el carácter de sus hijos, ni que la misión del padre sea la de educar en civilidad. Para que tal sucediera la mujer, por decisión propia, y dentro de una sociedad y mundo laboral completamente diferentes, tendría que quedarse en casa a cuidar de sus hijos hasta la edad de los cinco o seis años. Solo de este modo las tesis educativas de Unamuno se conformarían con la realidad. El gran reto de la humanidad es saber, pues, si la educación de los niños debe estar configurada en torno a la figura de la madre como antaño o si las guarderías pueden sustituirla con eficacia.

\section{La paternidad y la formación del "yo exterior"}

Cada padre haga de su hogar así como un templo, así también una escuela, y él mismo dé a comulgar a Dios y dé a comulgar a sus hijos el legado de la cultura humana (Unamuno 1971, 92).

Al igual que la maternidad, la paternidad es una secuela de la tensión ontológica de más vida, del conatus essendi, por lo tanto, y se concreta en dos ámbitos distintos de la realidad: en el biológico y en el espiritual. Para Unamuno, todo hombre solo se realiza si se hace padre y éste puede serlo o bien según la carne, o bien según el espíritu. Por ello, en este aspecto, maternidad y paternidad no se diferencian. En términos sinópticos, podríamos cristalizar el pensamiento de nuestro autor en las siguientes proposiciones. Para Unamuno, que dice inspirarse en Spinoza -aunque dicha inspiración implique algunas matizaciones como lo vio muy bien Álvarez Gómez (2003, 135-165) -, y en Schopenhauer, el primer principio del ser es el conatus essendi o la Wille zum Leben. Y al determinarlo de este modo, consideró que los instintos de conservación y de perpetuación, que, desde una perspectiva vitalista, se vinculan con la struggle for life de Darwin, constituían, dentro del mundo humano, el origen ontológico de las realidades de la maternidad y de la paternidad. Pues bien, fue precisamente esta relación ontológica entre el deseo de ser o la voluntad de vivir y las realidades de la maternidad y de la paternidad, lo que llevó a Unamuno a concluir que los conceptos de hombre y padre y los de mujer y madre eran, en sí mismos, consubstanciales, si no coextensibles, ya que, en términos ontológicos, tanto el hombre como la mujer nunca podrían realizarse existencialmente sino como padres y madres. Lo cual implica que, en Unamuno, la paternidad y la maternidad no son el resultado de una decisión humana 
sino de una exigencia ontológica, lo que desde nuestro punto de vista nos parece un planteamiento muy reductor del problema, en la medida en que creemos que el hombre, en cuanto ser libre, puede determinar su proyecto existencial de forma independiente de su naturaleza biológica, obviamente determinada, en términos ontológicos, por los instintos de conservación y de perpetuación. Asimismo, y desde nuestro punto de vista, que no coincide con el de Unamuno, ser padre o ser madre es tanto resultado de una pulsión ontológica como de una libre elección humana, que puede o no corroborar la mencionada pulsión. Pero, aunque no simpaticemos con la identificación que Unamuno establece entre los conceptos de hombre y padre y de mujer y madre, creemos más que oportuno el análisis de su concepción de paternidad, ya que la misma supone un conjunto de aportaciones muy sugestivas para comprender dicha realidad en los días de hoy.

Lo primero que hay que decir es que, en su extensa obra literaria, en sus novelas y teatro, por lo tanto, no hay ningún personaje angustiado o atormentado por el deseo de paternidad. Por ello, estamos forzados a admitir que, ya en este primer aspecto, hay una diferencia muy significativa entre sus personajes femeninos y masculinos, en la medida en que en su obra literaria no se hallan personajes masculinos del talante de Carolina de El marqués de Lumbría o de Gertrudis de La tía Tula. Pero, hay que preguntarlo, ¿cuál fue la razón que llevó a Unamuno a no crear personajes masculinos torturados por el deseo de paternidad? Desde nuestro punto de vista, hay dos motivos para que tal no sucediese. El primero es el que se refiere al hecho de que Unamuno haya quedado huérfano de padre a la temprana edad de seis años, lo que implicó que su concepción de familia y, por ende, su noción de educación familiar, hubiese quedado polarizada en torno a la "figura materna", es decir, a las figuras de su madre y abuela, doña Salomé y doña Benita, respectivamente. Y el segundo es el que se refiere a sus concepciones de maternidad y de paternidad o, si se quiere, a sus concepciones de matria o de patria, que implican, exclusiva y respectivamente, la vida familiar y la vida pública. O sea, el motivo de que no existan, en su extensa obra literaria, personajes masculinos polarizados en torno al deseo de paternidad se debe al hecho de que Unamuno haya creído que lo femenino y lo masculino tienen dos papeles bien distintos en la sociedad a raíz de sus propias vivencias familiares. O dicho de otro modo, dado que Unamuno, como cada uno de nosotros, es hijo natural de sus circunstancias o, si se quiere, de sus vivencias, con o sin consciencia de las mismas terminó por concebir el concepto de paternidad fuera del ámbito familiar, puesto que la muerte temprana de su padre le hizo perder el referente masculino dentro del mismo.

Hemos hecho hincapié en que en su extensa obra literaria no haya personajes masculinos polarizados en torno al afán de paternidad. Y lo hemos hecho bien. Sin embargo, si extendemos nuestra reflexión a su obra ensayística percibimos, por de pronto, que el concepto de paternidad referido al ámbito familiar, y por el momento nos referimos tan solo a este ámbito, está presente, de forma muy explícita, en su Agonía del cristianismo, de 1924. Basta no pasar por alto su capítulo X para percibir que, para nuestro autor, la realización del hombre, concebido en cuanto varón, implica también su desarrollo en el mundo familiar y, por ende, su resurrección en sus hijos carnales o espirituales. Por lo menos es esto lo que nos sugiere el comentario que Unamuno hizo de la vida del padre Jacinto Loyson, que abdicó del sacerdocio para casar con madame 
Meriman. Es más: si somos rigurosos, estamos incluso obligados a reconocer que Unamuno concibió el concepto de paternidad, en lo que se refiere al ámbito familiar, incluso dentro de su obra literaria, aunque ninguno de sus personajes principales, y esto es lo que queremos subrayar, pueda presentarse como un prototipo de la paternidad como ya lo hemos referido. Si se analizan, a título de ejemplo, su obra teatral La difunta, de 1909, y su obra novelística Niebla, de 1914, percibimos que, bajo un trasfondo señaladamente instintivo, tanto Fernando como Augusto Pérez se sienten atraídos por el sexo opuesto; atracción que está enfocada al matrimonio y a la paternidad, si se la interpreta a la luz de lo que representan los personajes don Eugenio de La princesa doña Lambra, de 1909, y don Emeterio de Un pobre hombre rico o Del sentimiento cómico de la vida, de 1933, dado que tanto el mencionado drama de 1909 como la novela de 1933 son comedias donde Unamuno criticó el descompromiso existencial de dichos personajes, cuyos matrimonios no conducían a la paternidad biológica o espiritual. Asimismo, estamos obligados a concluir que, en Unamuno, la paternidad está referida, también ella, al ámbito familiar. Prueba de ello son, por ejemplo, los personajes Antonio de Niebla, de 1914, y Joaquín Monegro de Abel Sánchez, una historia de pasión, de 1917, ya que ambos desean perpetuarse espiritualmente en sus descendientes, el primero en su hija adoptiva Rita y el segundo en su yerno, Abelín, y, después, en su nieto, Joaquinito. Por lo demás, puede incluso encontrarse el tema de la paternidad tanto en su dimensión biológica como espiritual en su drama proyectado Padre e hijo, en el cual Nicolás rechazaría a su padre biológico, don Anacleto, a favor de su padre adoptivo, Toribio. Sin embargo, y esto es lo fundamental, en Unamuno, la paternidad enfocada desde el ámbito familiar, que es a la que nos estamos refiriendo, tiene pocas implicaciones educativas, ya que es escasamente analizada por don Miguel y, cuando lo es, es más percibida como una secuela de la pulsión innata de más vida que como una realidad educativa fundamental. De este modo, y así considerada la concepción unamuniana de paternidad, estamos obligados a concluir que cada hombre está llamado, según Unamuno, a constituirse como padre, esto es, a casarse, a formar una familia y a tener hijos, ya que su proyecto existencial está vinculado con el impulso ontológico de más vida, que impele a todo hombre a perpetuarse en sus hijos. Pero ser padre no es tan solo engendrar sino, y de forma más radical, criar a un hijo, educándolo. Y esto lo sabía muy bien Unamuno. Fue por ello que, en su ensayo "Escarceos lingüísticos. A propósito de los dobletes", de 1899, alertó del hecho de que el carácter de los hijos se formase, fundamentalmente, a partir de la confluencia de las herencias fisiológica y educativa (Unamuno 1968b, 323). Y al plantear de este modo el problema, el rector salmantino tomó consciencia de que una correcta educación de las futuras generaciones debería empezar, dentro de las familias, a través de la asunción del deber paterno de educar sus hijos, con vistas a mitigar los defectos que puedan tener las referidas herencias. No nos extraña, pues, que, en la conferencia que pronunció en Málaga, el 21 de agosto de 1906, Unamuno haya afirmado que era deber de los padres saber qué problemas les han traído, en sus vidas, sus modos de ser para intentar que los mismos problemas no se verificasen de nuevo en las vidas futuras de sus hijos. Lo decisivo era, pues, que los padres, a través de la imitación, educasen ético-normativamente a sus hijos de tal forma que sus defectos no repercutiesen en ellos. 
(1) Engendrar un hijo de carne, simplemente engendrarlo, es placentero sin duda, pero no lo propio de un padre. Lo propio de un padre es criarlo, y criar un hijo es algo doloroso (Unamuno 1970, 348).

(2) La obligación que tiene todo padre es, después de haber visto qué dificultades o daños le ha traído la vida por su modo de ser, evitar que aquellos mismos daños o modo de ser análogo le lleven al hijo hacia los mismos males o desengaños de que él sufriera, por lo que es menester darles a los hijos personalidad y quitarles hipocresía, esta hipocresía que a todos nos mina el alma en estas ciudades corroídas por la anemia espiritual, en donde los hombres tienen dispersas sus facultades, y que son causa de que sean solo hombres de nombre u hombres de doble o de triple o de cuádruple personalidad: es decir, de ninguna (Unamuno 1971, 186).

Pero, en Unamuno, el concepto de paternidad dice más respecto al ámbito político que al familiar, aunque éste sea, como es obvio, inherente a los dos. Mas ¿en qué sentido está referido el concepto de paternidad al ámbito político? Para contestar a dicha cuestión habrá que tener presente el "Prólogo a la primera edición" de La tía Tula, de 1921. En dicha ocasión, Unamuno, apoyándose en la mitología griega, en concreto en los ejemplos de Antígona y de Creonte, quiso poner de relieve la diferencia que establecía, por aquel entonces, entre lo sororal y lo fraternal o, si se quiere, entre lo maternal y lo paternal, ya que, a su juicio, lo sororal y lo fraternal eran dos tipos bien distintos de filialidad que implicaban dos realidades bien distintas de la naturaleza humana: la domesticidad y la civilización (Unamuno 1967, 1042). Don Miguel, al plantear de este modo el problema, percibió que la maternidad se refería más a la vida familiar y la paternidad a la vida civil, siendo cierto que la civilización, la fraternidad, habría de apoyarse en la vida familiar o, si se quiere, en lo sororal y, por extensión, en lo maternal. Pero ¿qué significa la paternidad en Unamuno? Desde un punto de vista civil o político, la paternidad se refiere a la formación externa del yo, como nos lo sugiere el concepto unamuniano de obra (Unamuno 1968a, 70). Para Unamuno, todo hombre está llamado a hacer una obra social para que a través de la misma pueda formar su persona. En este sentido, cada hombre es padre de sus propias obras y éstas, sus hijos espirituales. Lo paternal se refiere, pues, a la formación de una obra, esto es, a la formación del yo externo. Si se analiza esta idea a la luz de los tres grados de perfección ética que Unamuno explicitó en su Del sentimiento trágico de la vida, de 1913, a través de la metáfora del zapatero, percibimos que hay una dimensión señaladamente ético-religiosa por debajo de su concepto de paternidad. No se trata de formar, tan solo, el yo-externo a partir del ejercicio de una determinada profesión u oficio, sino que esa profesión permita que el yo se forme ético-normativamente en el cuidado por sus semejantes (Unamuno 1969b, 207). Cada uno deberá ejercer de tal modo su profesión u oficio que a los ojos de sus feligreses merezca no morirse. Se trata, pues, no solo de formar un yo-externo sino también que ese yo pueda influir positivamente en los semejantes a partir de buenas obras, que han de ser, a su vez, el reflejo de buenos sentimientos. En este aspecto, San Manuel Bueno y Don Quijote son, dentro de la obra de Unamuno, dos ejemplos muy claros de paternidad política o civil. Son ejemplos de paternidad-de paternidad espiritual, civil y pública, se entiende-, porque ambos personajes, animados por buenos sentimientos, han intentado construir una obra pública y civil que no solo les permitiese construir sus propias personas, sino que alimentase de buenos anhelos a sus semejantes. Han 
sido, pues, cada uno a su modo padres de sus propias obras; padres, en primer lugar, de sí mismos, en cuanto constructores de sus propias personalidades, y, después, de los demás, en cuanto modelos de la espiritualidad, en el caso de San Manuel Bueno, de la espiritualidad de Ángela y de Lázaro; en el caso de Don Quijote, de Sancho. Cabría añadir, tan solo, que la paternidad, en cuanto potenciadora de la fraternidad, podría suponer, en Unamuno -y decimos podría suponer, porque Unamuno nunca lo dijo- la iniciación de los jóvenes en la vida pública. Si la acción de la madre se circunscribe a la esfera familiar y tiene por misión inculcar en sus hijos las normas de convivencia doméstica, la acción del padre, al circunscribirse a la esfera pública, debería iniciarlos en la vida civil. Ésta es una interpretación arriesgada pero legítima, si se tienen en cuenta las consideraciones anteriores, interpretadas a la luz del "Prólogo a la primera edición" de La tía Tula, de 1921. Con respecto a las implicaciones educativas del concepto de paternidad, en su ámbito civil y político, Unamuno, en la conferencia que pronunció en Málaga, el 21 de agosto de 1906, no dejó de afirmar que era necesario impugnar todos los "procedimientos que [...] aho[gan] la personalidad en hipocresía", siendo para ello necesario cambiar de método educativo, o mejor, haciendo que la maternidad, el mundo ético-normativo femenino, fuese el cimiento de la paternidad, esto es, del mundo jurídico-político masculino.

Y volviendo al culto al niño se hace preciso que cambiemos de método de educación y no eduquemos a nuestros hijos como a nosotros nos educaron nuestros padres. No queramos que nuestros hijos sean hechos como se nos hizo. Hay que combatir toda tendencia a que se repitan procedimientos que nos ahogaran la personalidad en hipocresía, y que cuando nuestros hijos lleguen a ser hombres no se vean atacados de la anemia espiritual que nos consume (Unamuno 1971, 186).

Si tenemos que valorar las propuestas educativas de Unamuno relativas a la educación familiar, lo primero que quisiéramos afirmar es que sus concepciones de maternidad y paternidad no se adecuan a los días de hoy, no solo porque son anacrónicas, sino también porque se alejan de la realidad. Si somos rigurosos verificamos que su deseo de polarizar, de forma rígida y estricta, sus concepciones de maternidad y de paternidad a los ámbitos familiar y público, respectivamente, es un tanto exagerado, sobre todo cuando Unamuno parece restar cualquier importancia a la figura paterna dentro del mundo familiar. En los días de hoy, ni lo femenino es una señal de vida familiar, ni lo masculino de vida civil, ya que ambos se refieren, simultáneamente, a la vida familiar y pública. De este modo, interpretada su obra a la luz de nuestros días, nos causa extrañeza que Unamuno, al lado de Gertrudis, no haya dibujado un personaje masculino atormentado por el ansia de paternidad espiritual. Sin embargo, si desvinculamos sus concepciones de familia y de civilidad de las nociones de madre y padre, creemos que la obra de Unamuno puede tener gran significado hermenéutico. Y puede tenerlo -decíamos-, porque creemos que la familia (y quien dice la familia dice el padre y la madre, lo desee o no Unamuno) tiene la misión de formar el yo-interior de los individuos, de formar sus personalidades, bajo una dimensión ético-normativa, que ha de ser la base espiritual de la propia civilidad o del mundo político, donde el yo-externo de cada individuo ha de formarse. O sea, para nosotros, son muy aceptables, 
en sus líneas generales, sus nociones de vida familiar y civil siempre y cuando éstas no se reduzcan estricta y respectivamente a lo femenino y a lo masculino.

\section{Las niñeras, las nodrizas y los personajes extranaturales, y su sinsentido educativo}

Hay, además, una pedagogía de adaptación al maestro, o sea del menor esfuerzo. Las madres, nodrizas, amas secas, rollas y nurses han encontrado maneras de manejar a los niños pequeñuelos que son las más cómodas para las que los manejan, no para ellos mismos. A esto obedecen las mantillas. Se busca una transición o compromiso entre la comodidad y bienestar del niño y la comodidad y el menor esfuerzo de la niñera. Y casi me atrevo a afirmar que los cirujanos, por su parte, han hallado aquellos procedimientos que produzcan la menor molestia también y el menor mal trabajo del operador. Es un problema de máximos y de mínimos. $\mathrm{Y}$ es muy humano que de tener que sacrificar uno u otro interés de la niñera, y hasta la madre, sacrifiquen el del niño al suyo propio, y el cirujano, por salir del paso o no darse demasiado trabajo, ampute un miembro que se pudo conservar con cuidados. Sobre todo si el paciente es pobre (Unamuno 1913).

Si se lee con algún detalle la obra de Unamuno, sobre todo los pasajes de la misma en los cuales su autor se detiene en la educación familiar, llegamos a la conclusión de que el rector salmantino estaba en contra de las niñeras y nodrizas, así como, y quizás con mayor relieve, de los personajes extranaturales que inculcan a los niños para que éstos no den guerra en casa. La sensación que nos queda de la lectura del texto unamuniano es la de que nuestro autor era un acérrimo partidario de una educación familiar estructurada en torno a los padres, fundamentalmente en torno de la figura de la madre. Y que por ello era reacio a considerar como benéfica la inclusión de las niñeras y de las nodrizas en la educación familiar. La sensación que nos queda, pues, es que la educación familiar era, para Unamuno, un deber moral, casi religioso, que debería ser asumido por los propios padres, más allá y más acá de sus necesidades de orden económico. Era, en suma, un deber absoluto. Basta no pasar por alto la razón que da para la caída del Imperio Romano para percibir que, a su juicio, la decadencia de la sociedad romana se debió al descompromiso de las familias ricas con respecto a la educación de sus hijos, que los han entregado a lo que denominó "pedagogos de alquiler". Y forzoso es aceptar que nadie en el mundo, por lo menos en un cuadro de normalidad, tendrá mayor amor a un niño que sus padres biológicos o espirituales. Por ello, en términos ideales, nos parece más que aceptable el posicionamiento de Unamuno, en la medida en que creemos que los padres deben ser los primeros interesados en la educación de sus hijos. Y no solo en este aspecto sino también en la importancia que los padres tienen con respecto a las niñeras y nodrizas. Nos parece más que evidente, si la sociedad así lo permitiera, que era más ventajoso para el niño que su educador, hasta la edad de entrar en la escuela, fuese uno de sus padres, fundamentalmente la madre, que una niñera o nodriza, puesto que creemos que por más importantes que sean las guarderías en el desarrollo cognitivo y afectivo de los niños jamás podrán sustituir el amor de la madre. Lo cual quiere decir que, en este aspecto, la propuesta de Unamuno 
se presenta grosso modo como un ideal al que hay que tener siempre presente, aunque la sociedad actual no lo permita concretar. Quizás un día la humanidad se haga más sensible a los efectos benéficos que la presencia de la madre tiene en la formación éticonormativa de los niños y permita que ésta, en el caso de que sea ese su deseo, se pueda quedar en casa a cuidar de sus hijos hasta la edad en que éstos entren por primera vez en la escuela, sin que ello implique cualquier pérdida de sus derechos laborales. Pero aunque comulguemos con Unamuno en cuanto a que, en términos ideales, la mejor educación para el niño es la "tradicional", aquella que se realiza en los pueblos alrededor de la figura de la madre y de los abuelos y en contacto con los demás niños, lo cierto es que la vida moderna no lo permite, y por ello las nodrizas y las niñeras tienen un papel muy importante en la educación de las jóvenes generaciones, lo desee o no Unamuno. Asimismo, lo que hay que pedir es que ellas, las niñeras y las nodrizas, así como las guarderías, tengan sentido de la responsabilidad y no ejerzan su oficio o misión en un cuadro de mínimos, sacrificando el soberano interés del niño a sus intereses particulares, como percibió muy bien Unamuno, ya que, como tuvo ocasión de puntualizar en sus Recuerdos de niñez y de mocedad, de 1908, es el recuerdo de la niñez el que vivifica el alma del hombre adulto (Unamuno 1970, 154). Por otro lado, Unamuno percibió también que, al niño, en su camino existencial, se le abren muchas posibilidades y que al abrirse a unas se cierra a las otras y que, por ello, lo fundamental es que el padre o el educador esté siempre presente para que el niño elija, tanto cuanto sea posible, las mejores posibilidades en la formación de su ser (Unamuno 1971, 88).

Lamentándome yo de la ceguera de un pobre niño, producida por la viruela, su madre, que estaba presente, al preguntarle por qué no le había lavado los ojos, me contestó: "Pero si se llenaban de pus a cada diez minutos". Y repicando yo: "Pues lavárselos cada diez minutos", me dijo estas fatídicas palabras que me dejaron helado: "Vaya un trabajo". ¡Y era su madre! (Unamuno 1913).

En lo que estamos completamente de acuerdo, y sin ninguna reserva, es con su negativo parecer con respecto a la existencia de los personajes extranaturales. Para Unamuno, el "Coco", ese terrible "Espíritu de las Tinieblas", el "Papau" o la "Marmota" (Unamuno 1970, 119) eran seres ficticios, profundamente nefastos, creados por las nodrizas y por los padres para sujetar a los niños. Pues bien, a su juicio, la existencia de dichos personajes extranaturales, grabados en la consciencia de los niños en sus primeros años de vida, hacía que el primer principio sobrenatural [de la conciencia humana] fuese un principio malo, tenebroso y amenazador, cuyo aliento casi nunca logra desaparecer del hondón de la consciencia de los adultos y que, por ello, supone efectos muy negativos en la formación de la personalidad humana (Unamuno 1970, 119). Es por ello que no podemos estar más de acuerdo con Unamuno en cuanto a la necesidad de su desaparición. Y no podemos estar más de acuerdo -decíamos-, porque no hay necesidad de impregnar la consciencia de los niños de seres extranaturales, siempre de índole maléfica, en la medida en que aquéllos, desde muy pronto, comprenden lo que los padres les quieren trasmitir. Lo que hay que fomentar es, desde el primer momento, el espíritu de responsabilidad. Por otro lado, lo que hace una realidad digna de ser vivida, como la familia, no es el terror sino el amor. Y en esto volvemos a estar en 
plena sintonía con Unamuno. Porque una cosa es tener una moral puramente negativa, la de que no se puede hacer esto o aquello por miedo a esta o aquella realidad, y otra, completamente diferente, es tener una moral positiva, la que exige hacer esto o aquello por amor al bien común o individual. No nos extraña, pues, que Unamuno se indignase con el hecho de que los personajes extranaturales imprimiesen en la consciencia de los niños, como primer principio sobrenatural, un principio malo y tenebroso, cuando el carácter de este primer principio debería ser de naturaleza completamente opuesta, es decir, cuando su naturaleza debería ser consubstancial al bien moral.

El niño aborrece y teme la oscuridad, que las nodrizas, para poder gobernarlo, han poblado de seres tenebrosos. En lo oscuro puede el niño tropezar y caer, rompiéndose la cabeza; la oscuridad lleva consigo todas las tristezas de la ceguera. El cuarto oscuro es el infierno, poblado por la fantasía con toda clase de Cocos. En él, el niño se tapa los ojos y se vuelve contra la pared para que el Coco no le vea. Y ni aun así deja el niño de verle, es decir, ni aun así deja el Coco de ver al niño. Más claro le ve cuanto más oscuro está (Unamuno 1970, 119).

\section{Conclusiones}

Se sacan dos conclusiones del pensamiento unamuniano. La primera es que la familia tiene una misión antropagógica* decisiva y sustancial que no puede soslayar: la de mantener la unidad y continuidad biopsíquica del pueblo al que pertenece. Y la segunda es la de que los padres, según sus rasgos psicosomáticos propios, tienen misiones educativas bien diferenciadas: la de formar el yo-interior y el yo-exterior de sus hijos.

Dado que la distinción entre padre y madre ya no puede ser defendida como en el tiempo de Unamuno, las distintas misiones educativas de los progenitores que nuestro autor nos propone no deben ser leídas hoy como una exigencia de una vuelta en el tiempo o de un deseo de un regreso al pasado, sino más bien como una posibilidad de interpretar las obligaciones educativas de ambos progenitores, que han de educar, conjunta y simultáneamente, a sus hijos en la dimensión ético-normativa y jurídicopolítica de la existencia humana, que, cándidamente, hoy se pide a la escuela.

Si para algo sirve leer a los autores clásicos no es seguramente para comprender el pasado como un absoluto per se, cuyo trabajo hermenéutico solo es meritorio cuando las ideas y representaciones de antaño nos permiten comprender mejor las exigencias sociales, políticas y educativas de nuestro mundo actual. Es por ello que, si alguna importancia educativa y filosófica tiene el texto unamuniano, esa es sin duda la de ayudarnos a comprender el hecho de que todas las familias tienen un deber que cumplir y que jamás pueden olvidar, sobre todo en estos tiempos hedonistas en que vivimos que miran de reojo todo lo que implica esfuerzo y sacrificio, como la formación de los hijos.

Se trata de un neologismo. 
La idea de que el cimiento de la libertad es el espíritu del pueblo tampoco puede ser olvidada. No hay educaciones neutrales. Y no las hay, porque la cultura no es neutra. Y de serlo así, hay que educar a las futuras generaciones según el modelo axiológico de las generaciones pasadas. El ideal romántico de la unión de los individuos de una determinada comunidad en torno al espíritu del pueblo, tan querido por Unamuno, no debería ser abandonado. Pero, con ello, muy lejos de que se proponga el cierre de fronteras a lo extranjero, lo que se pide es que todos los pueblos, a partir de un diálogo intercultural, formen su ipseidad cultural a partir del ideal humano que dormita en el concepto unamuniano de intrahistoria.

El diálogo de todos los pueblos en búsqueda del ideal humano, sin pérdida de lo castizo, es decir, la tesis del primer Unamuno, es una propuesta educativa que merece ser recuperada. Si lo universal, lo humano, es un horizonte asintótico que camina y crece a partir del diálogo intercultural, ¿cómo puede ese universal continuar alumbrándonos en la búsqueda de lo humano si destruimos lo nacional donde tiene sus raíces? Ésta sería la cuestión que nos plantearía hoy Unamuno y en la forma como la contestemos decidiremos el provenir de nuestras futuras generaciones.

\section{Referencias bibliográficas}

FUENTES

Unamuno, M. (22.XII.1913), "Otro arabesco pedagógico", Los Lunes de "El Imparcial”. Archivo Casa Museo Unamuno. (1966), Obras Completas I. Madrid: Escelicer. (1967), Obras Completas II. Madrid: Escelicer. (1968a), Obras Completas III. Madrid: Escelicer. (1968b), Obras Completas IV. Madrid: Escelicer. (1968c), Obras Completas V. Madrid: Escelicer. (1969a), Obras Completas VI. Madrid: Escelicer. (1969b), Obras Completas VII. Madrid: Escelicer. (1970), Obras Completas VIII. Madrid: Escelicer. (1971), Obras Completas IX. Madrid: Escelicer. (1996), Epistolario Americano 1890-1939. Salamanca: Ediciones Universidad de Salamanca.

\section{BIBLIOGRAFÍA SECUNDARIA}

Aguilera, C. (oct.-dic.1965), "Pensamiento educacional de D. Miguel de Unamuno", Calasancia 11, 44: 405-523.

Álvarez Gómez, M. (2003), Unamuno y Ortega: La búsqueda azarosa de la verdad. Madrid: Biblioteca Nueva. 
Barros Dias, J. M. (2002), Miguel de Unamuno e Teixeira de Pascoaes: compromissos plenos para a educação dos povos peninsulares. Lisboa: Imprensa Nacional Casa da Moeda.

Blanco Prieto, F. (2011), Unamuno, profesor y rector en la Universidad de Salamanca. Salamanca: Hergar Ediciones Antema.

Cardwell, R. A. (2000), "Miguel/Mijail: La (dia) lógica de Amor y pedagogía", en C. Flórez Miguel, coord., Tu mano es mi destino. Salamanca: Ediciones Universidad de Salamanca; pp. 47-58.

Cifo Gonzalez, M. (2005), “Amor y pedagogía o el problema de la educación visto por Miguel de Unamuno", en A. Chaguaceda Toledano, ed., Miguel de Unamuno. Estudios sobre su obra. II. Salamanca: Ediciones Universidad de Salamanca; pp. 329-347.

Cruz Hernández, M. (1952), "La misión socrática de Unamuno", Cuadernos de la Cátedra Miguel de Unamuno 3: 41-53.

Delgado Criado, B. (1973), Unamuno educador. Madrid: Editorial Magisterio Español.

Espino Gutiérrez, G. (1965-1966), "El maestro Fray Luis de León y el maestro Unamuno", Boletín de la Universidad Compostelana 73-74 (2): 107-117.

Flórez, R. (1987), "Sistema de pensamiento y razón educativa en Unamuno", Cuadernos Hispanoamericanos 440-441: 187-204.

Forgione, J. D. (1920), Miguel de Unamuno: sus ideas pedagógicas. Unamuno y la Universidad de Salamanca. Buenos Aires: Imp. Asiática.

Frayle Delgado, L. (1990), "La dialéctica del eros en 'Amor y Pedagogía"”, AZAFEA. 3: $265-283$.

García Blanco, M. (jul.-dic. 1961), “Amor y pedagogía, nívola unamuniana”, La torre 9, 35-36: 443-478.

Gil, M. L. (jun. 1979), "La educación como materia novelesca. Paul Bourget Unamuno - Pérez de Ayala", Cuadernos Hispanoamericanos 348: 596-608.

Gómez de la Torre, I. B. (2000), "Unamuno y la Universidad: rector e intelectual”, en C. Flórez Miguel, coord., Tu mano es mi destino. Salamanca: Ediciones Universidad de Salamanca; pp. 47-58.

Gómez Molleda, Ma . D. (1997), "Unamuno, rector regeneracionista", Revista de educación. №. extra: 137-147.

Herrero Castro, S. (1991), "Pensamiento socio-educativo de Miguel de Unamuno: estructura y cambio social en la España del primer tercio del siglo XX", Studia Paedagogia 22: 55-79.

Moralejo Laso, A. (1966), "Don Miguel de Unamuno, profesor de griego y de historia de la lengua castellana: impresiones y recuerdos de un alumno", en AA.VV. Homenaje al Prof. Alarcos. Valladolid: Universidad de Valladolid; pp. 329352.

Morasverdes, E. Ch. (pseudónimo) (05.V.1906), "Páginas pedagógicas. Unamuno catedrático", La Iberia. Semanario Independiente 4, 159: p. 4. 
Morón Arroyo, C. (1997), “'Alma nacional': el trasfondo sociológico de En torno al casticismo", en Th. Berchem y H. Laitenberger, coords., El joven Unamuno en su época. Actas del coloquio internacional Wurzburg 1995. Valladolid: Junta de Castilla y León - Consejería de Educación y Cultura; pp. 25-26.

Roberts, S. (2007), Miguel de Unamuno o la creación del intelectual español moderno. Salamanca: Ediciones Universidad de Salamanca.

Rubio Latorre, R. (1973), Unamuno educador, Cuadernos de la Cátedra Miguel de Unamuno 23: 27-47.

Senabre, R. (1989), "Los arquetipos temáticos en la literatura unamuniana”, en Ma. D. Gómez Molleda, ed., Actas del Congreso Internacional del Cincuentenario de Unamuno. Salamanca: Ediciones Universidad de Salamanca; pp. 165179.

Turin, Y. (1982), Miguel de Unamuno Universitaire. Paris: S.E.V.P.E.N.

Valdés, M. J. (1963), ““Amor y pedagogía’ y lo grotesco”, Cuadernos de la Cátedra Miguel de Unamuno 13: 53-62. 